\title{
Designing a prototype for Mentally Challenged and Alzheimer Patients
}

\author{
Dr. K. Saravanan*1, Abhinav Anand ${ }^{2}$, Chinmaya Kumar Nayak², Ayush Anand², Deepak Kumar ${ }^{2}$ \\ *1Professor, Department of Information Science, New Horizon College of Engineering, Bangalore, Karnataka, India \\ ${ }^{2}$ Student, Department of Information Science, New Horizon College of Engineering, Bangalore, Karnataka, India
}

\section{Article Info}

Volume 7, Issue 4

Page Number: 262-264

Publication Issue :

July-August-2021

Article History

Accepted : 15 July 2021

Published : 22 July 2021

\section{ABSTRACT}

This work is the prototype of this system is mobile application which uses the GPS technology to track the patient and it help the gathering of information from satellites in order to find the exact coordinate of the Alzheimer patient, whenever the patient move away fro thr specific boundary which is given in the tracker like mobile and the mobile tracks the GPS location and the location send a message in the computer or smartphone through the cellular network system that the patient is out of location or boundary.

Keywords : Mobile App, React-Native, Full-Stack Project, Helping Alzeimer Patients.

\section{INTRODUCTION}

We present the user entered development process for a GPS monitoring system that can be used for the dementia care to support care for persons with wandering behaviour. The usage of GPS system in dementia care is still very low. So we takes a socio technical stance on development of the the GPS technology in dementia care and assesses the practical and ideological issues surrounding care to understand. The result include the qualitative user studies from which design ideas, implications and requirements for the design and redesign were developed. Descriptions of the politics, negotiation and challenges encountered in the project at hand. The design process was taken as a whole to illuminate the way in which design outcomes are arrived at and to foster discussion about how "best practise" nightly be achieved.
So, we proposed the system which helps the patient to track if they escape also from the hospital and if the went outside of the home. The patient will be provided an anklet who is suffering from the diseases. The anklet have the GPS tracker system which helps to track the patient and it send the present location to the care taker. It continuously provide a message to the care taker that the patient is escape from the hospital or they lost their home.

\section{SCOPE OF THE PROJECT}

The scope of this project is, the prototype is made to gather the information about the Alzhemier patients. It's like an application which helps to track the patient if the patient is run away from the hospital or from the home. This helps the family member to find and track the patient if the patient move away from their specific boundary. In this application the distance is given in which the patient can free to

Copyright: (C) the author(s), publisher and licensee Technoscience Academy. This is an open-access article distributed under the terms of the Creative Commons Attribution Non-Commercial License, which permits unrestricted non-commercial use, 
move. If the patient move away from the specific given distance in the application then it provide an alert message to the care taker and the care taker can track the patient easily. Due to this project it will be easy to the care taker and the family member to take care the patient. It is not necessary to always look after the patient. The Alzheimer patient who is admitted in the ward may be ran away from the ward or from given specific given boundary. Same things may happen in the mental hospital also, although the security is there but also there may be a chance to escape of the patient from the hospital. Because it is not possible to look every time to the patient. Sometime patient may escape from the hospital and ran away. To prevent this activities the project is made to protect the patients.

\section{RESULTS AND DISCUSSION}

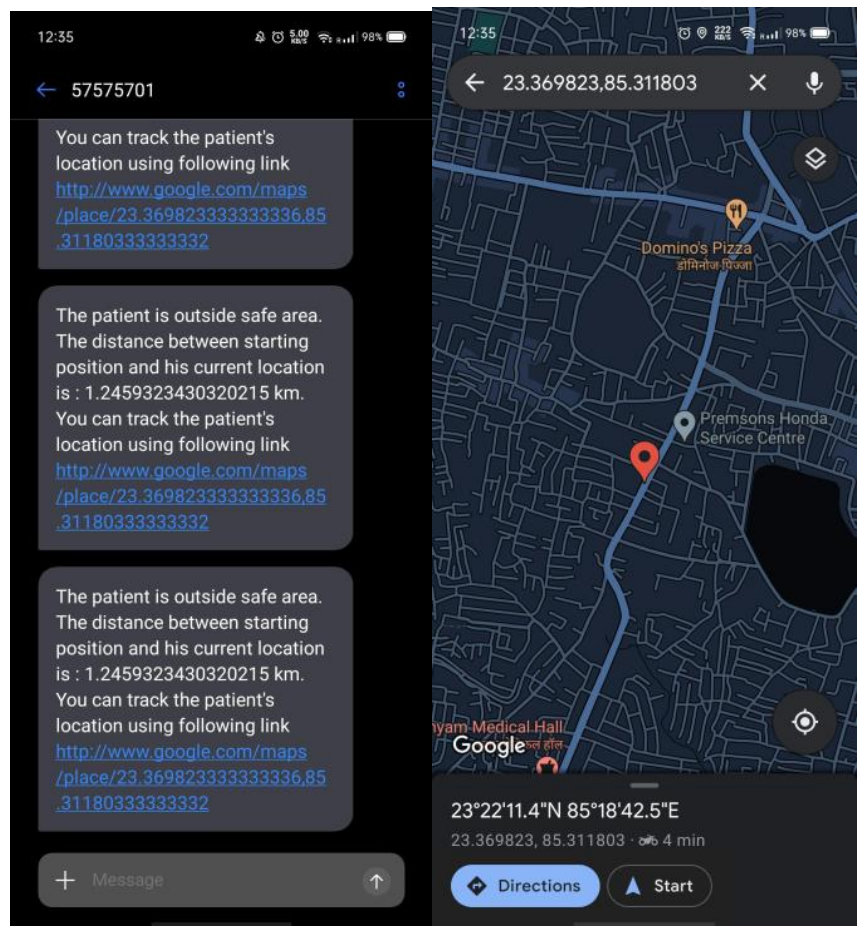

The Alzhemier patients are admitted in the hospital and they are in the specific ward. They are kept in the safe zone so they can stay safe and they are care by the care taker. Some time what happen it is not necessary that security person is available every time.
At same time patients may ran away or come out from the safe zone.

At the end of project. Caretaker will get sms like this if Alzheimer patient tries to go outside geofencing area. And on clicking on that link, caretaker can navigate to the Alzheimer patients using google map.

A. Different Modules of the Project

- User Authentication : User Authentication module is used to authenticate users into the system. This module handles the signing up and signing all types of users into the system. This module is responsible for storing all the user data.

- Tracker : It tracks the location of the patient using Geofencing and Google map library. This module is responsible for storing the paths travelled by the user.

- Sending alert message : This module sends an alert message and patients current location if the patient's location is out of the specified area .

B. System Architecture

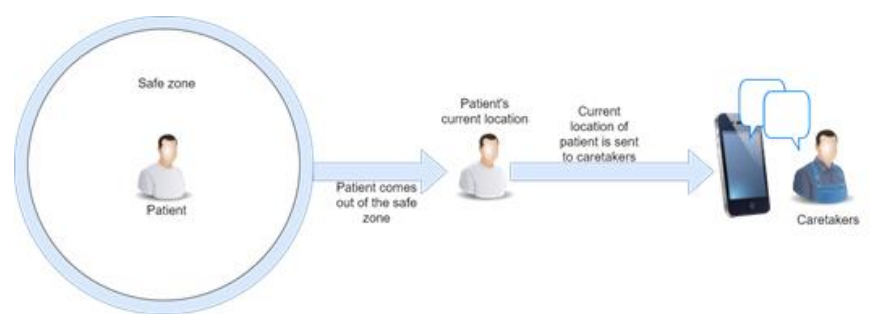

Is such activities occur then the tracker given to the patients track the current location to that specific patients and provide an alert message that patient is out of specific boundary so it helps to find out the patients and get back the patients again the hospital. It may be a great risk if the patients move away from the ward. Patients may face different kind of problems because they are mentally disturbed. So to prevent from all these activities the prototype is designed. 


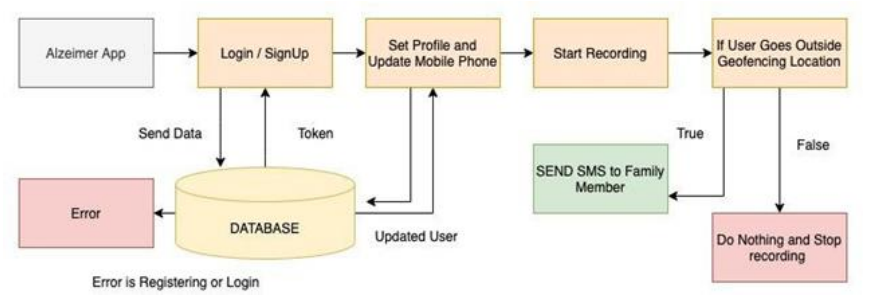

C. Flowchart

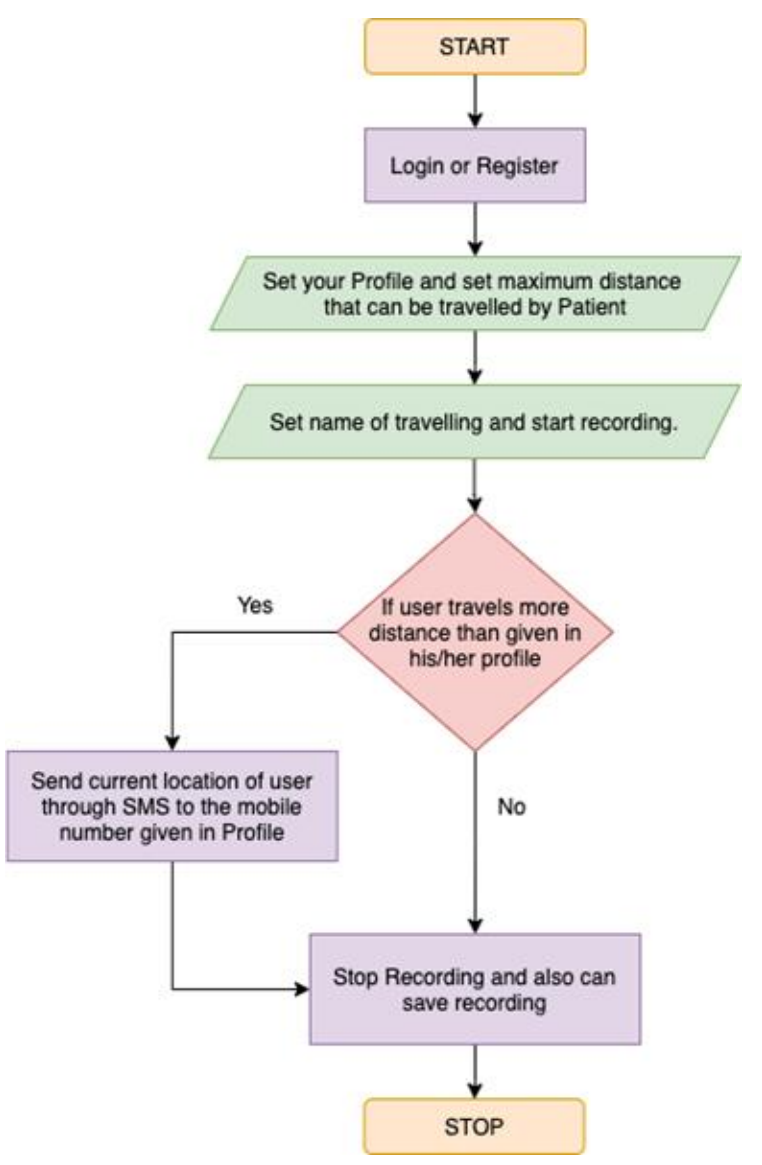

IV. CONCLUSION

This project was about to take care the Alzheimers patient who run away from the hospital and from their ward. It's provide the tracker system through which the patient can easily track and can catch the patient easily who run away or lost their way. The purposed of this app is it uses a GPS technologies which is used to gather the information and find the coordinates of the patients when the patients move away from the boundary. It will sent the message through the signal in their computers and smartphones. If a mentally challenged patient has wandered outside their home.

\section{REFERENCES}

[1]. SARA PAIVA, CARLOS ABREUm, Why Location Devices are Relevant in Managing Dementia

[2]. KATRINA BISHOP, What Will They Wear?

\section{Cite this article as :}

Dr. K. Saravanan, Abhinav Anand, Chinmaya Kumar Nayak, Ayush Anand, Deepak Kumar, "Designing a prototype for Mentally Challenged and Alzheimer Patients", International Journal of Scientific Research in Computer Science, Engineering and Information Technology (IJSRCSEIT), ISSN : 2456-3307, Volume 7 Issue 4, pp. 262-264, July-August 2021. Available at doi : https://doi.org/10.32628/CSEIT217474 Journal URL : https://ijsrcseit.com/CSEIT217474 